\title{
OJS OPEN

\section{INFOGRÁFICOS: ESTRATÉGIAS PARA O DESENVOLVIMENTO DAS COMPETÊNCIAS EDUCACIONAIS NO ENSINO DA GEOGRAFIA}

\author{
José Gustavo da Silva Melo; ; Lucas Gabriel da Silva²; Luiz Augusto Ferreira de Campos \\ Viana $^{3}$
}

\begin{abstract}
${ }^{1}$ Universidade Federal de Pernambuco, Mestre em Desenvolvimento Urbano, pelo programa de pós-graduação em Desenvolvimento Urbano (MDU/UFPE). E-mail: gustavodasilvamelo@gmail.com. Orcid: http://orcid.org/0000-0003-2876-8129

${ }^{2}$ Especialista em Docência com Ênfase na Educação Básica, pelo programa de pós-graduação do Instituto Federal de Minas Gerais - Campus Arcos (IFMG-Arcos). E-mail: lucas.g.silva@hotmail.com.br. Orcid: http://orcid.org/0000-0003-4848-4027

${ }^{3}$ Coordenador e Professor da Pós-graduação em Docência com Ênfase na Educação Básica, no do Instituto Federal de Minas Gerais - Campus Arcos (IFMG-Arcos); Mestre Engenharia de Materiais, pela Universidade Federal de Ouro Preto (UFOP). E-mail: luiz.viana@ @ifmg.edu.br. Orcid: http://orcid.org/0000-0001-5475-8077
\end{abstract}

Artigo recebido em 15/11/2020 e aceito em 18/06/2021

\begin{abstract}
RESUMO
Os Infográficos são gêneros multimodais compostos, em que se fundem texto verbal e imagem. A disciplina de Geografia compõe o inventário das "Matérias" curriculares da Educação Básica, tendo por desígnio contribuir para a constituição do cidadão participativo, promovendo nesse, o conhecimento e a organização do espaço local, nacional e mundial, assim como as inter-relações desse com o meio que o cerca. Logo, amparado nestas considerações, essa proposta de pesquisa sugere discutir, as potencialidades do uso de diversas linguagens, no processo de aprendizagem dos aprendizes, por meio da construção de infográficos no âmbito do ensino de Geografia utilizando plataformas digitais. A pesquisa teve como campo, turmas do $2^{\circ}$ ano do Ensino Médio, em uma cidade do interior do Ceará. O estudo se justifica pela necessidade de pensar um ensino da Geografia que esteja alinhado às novas demandas da sociedade contemporânea em relação à comunicação ao fazer uso de vários tipos de linguagens. A pesquisa enfoca um viés metodológico do tipo qualitativa. O estudo utilizou o método dedutivo, apresenta-se neste estudo o desenvolvimento de uma proposta metodológica experienciada com aprendizes do Ensino Médio na disciplina de Geografia voltada a produção de infográficos através da Plataforma Digital Canva. Os resultados apontam que o uso e produção dos infográficos combinado com um processo de educar pela pesquisa é um recurso de muitas potencialidades no processo de aprendizagem dos aprendizes por agregar variação nas diversas linguagens e simbologias, como também por possibilitar vários estilos de aprendizagem.
\end{abstract}

Palavras-chave: educação básica; linguagens não-verbais; ensino-aprendizagem; sociedade da informação. 


\title{
INFOGRAPHICS: STRATEGIES FOR THE DEVELOPMENT OF EDUCATIONAL SKILLS IN GEOGRAPHY
}

\begin{abstract}
Infographics are composite multimodal genres, in which verbal text and image merge. The subject of Geography composes the inventory of the curricular "Subjects" of Basic Education, with the purpose of contributing to the constitution of the participative citizen, promoting in this, the knowledge and organization of the local, national and global space, as well as the interrelations of this with the environment that surrounds it. Therefore, supported by these considerations, this research proposal suggests discussing the potential of using different languages in the learning process of learners, through the construction of infographics within the scope of teaching Geography using digital platforms. The research had as field, 2nd year high school classes, in a city in the interior of Ceará. The study is justified by the need to think about a teaching of Geography that is aligned with the new demands of contemporary society in relation to communication when using various types of languages. The research focuses on a qualitative methodological bias. The study used the deductive method, it is presented in this study the development of a methodological proposal experienced with high school learners in the Geography discipline aimed at the production of infographics through the Canva Digital Platform. The results show that the use and production of infographics combined with a process of educating through research is a resource with many potentials in the learning process of learners by adding variation in different languages and symbologies, as well as by enabling various learning styles.
\end{abstract}

Keywords: basic education; non-verbal languages; teaching-learning; information society.

\section{INFOGRAFÍAS: ESTRATEGIAS PARA EL DESARROLLO DE LAS COMPETENCIAS EDUCATIVAS EN LA ENSEÑANZA DE LA GEOGRAFÍA}

\section{RESUMEN}

Las infografías son géneros multimodales compuestos, en los que el texto verbal y la imagen se fusionan. La asignatura de Geografía compone el inventario de las "Asignaturas" curriculares de Educación Básica, con el propósito de contribuir a la constitución del ciudadano participativo, promoviendo en este, el conocimiento y organización del espacio local, nacional y global, así como las interrelaciones de este con el entorno que lo rodea. Por tanto, sustentada en estas consideraciones, esta propuesta de investigación sugiere discutir el potencial del uso de diferentes idiomas en el proceso de aprendizaje de los educandos, a través de la construcción de infografías en el ámbito de la enseñanza de la Geografía utilizando plataformas digitales. La investigación tuvo como campo, las clases de segundo año de secundaria, en una ciudad del interior de Ceará. El estudio se justifica por la necesidad de pensar en una enseñanza de la Geografía acorde con las nuevas demandas de la sociedad contemporánea en relación a la comunicación al utilizar diversos tipos de lenguajes. La investigación se centra en un sesgo metodológico cualitativo. El estudio utilizó el método deductivo, se presenta en este estudio el desarrollo de una propuesta metodológica vivida con estudiantes de secundaria en la disciplina Geografía dirigida a la producción de infografías a través de la Plataforma Digital Canva. Los resultados muestran que el uso y producción de infografías combinado con un proceso de educación a través de la investigación es un recurso con muchas potencialidades en el proceso de aprendizaje de los alumnos, ya que agrega variación en diferentes lenguajes y simbologías, además de posibilitar varios estilos de aprendizaje.

Palabras clave: educación básica; estrategia metodológica; enseñanza-aprendizaje; el conocimiento científico. 


\section{INTRODUÇÃO}

O ambiente escolar é o espaço mais adequado para o desenvolvimento de um programa de educação. Diferencia-se das demais instituições por ser a que proporciona a possibilidade de educar por meio da construção de conhecimentos, decorrentes da confrontação dos diversos saberes. Ou seja, aqueles abrangidos no conhecimento científico, vinculados pelas distintas disciplinas e aqueles trazidos pelos aprendizes e seus familiares, ao expressarem suas crenças e valores culturais próprios. Há também os saberes apresentados pelos professores, formados ao longo de sua experiência resultante de vivências históricas, abarcando crenças e expressões, originadas em atitudes e comportamentos apreendidos.

O ambiente escolar é o espaço mais adequado para o desenvolvimento de um programa de educação. Diferencia-se das demais instituições por ser a que proporciona a possibilidade de educar por meio da construção de conhecimentos, decorrentes da confrontação dos diversos saberes. Ou seja, aqueles abrangidos no conhecimento científico, vinculados pelas distintas disciplinas e aqueles trazidos pelos aprendizes e seus familiares, ao expressarem suas crenças e valores culturais próprios. Há também os saberes apresentados pelos professores, formados ao longo de sua experiência resultante de vivências históricas, abarcando crenças e expressões, originadas em atitudes e comportamentos apreendidos.

Por sua vez, o ensino de Geografia tem desbravado novas experiências com a disseminação de informações derivadas do contexto da tão falada revolução tecnológica. Assim, ensinar e aprender, na dita Sociedade da Informação1, exige conhecimento e domínio de linguagens variadas que não se limitam apenas ao aspecto verbal.

Além da linguagem verbal, obviamente expressa pelos textos, deve-se considerar também a linguagem visual que cada vez mais se torna comum na realidade em que vivem os aprendizes. Desta forma, os infográficos podem ser uma excelente ferramenta para os aprendizes que tenham predominância de um estilo de aprendizagem visual, para facilitação no

\footnotetext{
${ }^{1}$ A expressão "sociedade da informação" passou a ser utilizada, como substituto para o conceito "sociedade pósindustrial", afim de transmitir o conteúdo específico do "novo paradigma técnico-econômico". Constitui assim, uma tendência dominante mesmo para economias menos industrializadas e define o paradigma da tecnologia da informação. (SANTOS NETO; ALMEIDA JUNIOR; VALENTIM, 2013).
} 
processo de construção do conhecimento em Geografia e suas competências proposta enquanto disciplina escolar.

Por conseguinte, a disciplina de Geografia compõe o inventário das matérias curriculares da Educação Básica, tendo por desígnio contribuir para a constituição do cidadão participativo, promovendo nesse, o conhecimento e a organização do espaço local, nacional e mundial, assim como as inter-relações desse com o meio que o cerca. Logo, entender a sociedade como um todo e não como uma parte díspar, é a finalidade teórica e prática da Geografia. Para tal, recorre a leitura do mundo, da vida e do espaço vivido (BRASIL, 2013).

Nesse contexto educacional, expõem-se que Infográficos são gêneros multimodais compostos, em que se fundem texto verbal e imagem. Tal recurso discursivo é comum nos domínios do jornalismo e da publicidade, entretanto, é pouco utilizado no ambiente escolar. Todavia as pressuposições que o fazem abranger e serem utilizados pelos campos da mídia e da comunicação são sua ampla capacidade de absorção pelas diversificadas formas de interagir com o leitor.

Nesse contexto, Kanno (2018), com base nos infográficos dos livros didáticos, adiciona acepção:

\begin{abstract}
A infografia propicia, ainda, o contato com múltiplas linguagens e valoriza as representações cartográficas, contribuindo, portanto, para o letramento linguístico e cartográfico. Infográficos servem para transmitir informações de maneira visual; são, assim, úteis para dar mais dinamismo à leitura, oferecendo possibilidades de práticas pedagógicas diversificadas, em que os aprendizes devam buscar os dados e "destrinchar" a narrativa em debates e discussões de grupo. Trata-se, portanto, de um recurso pedagógico valioso. Há também a questão estética: as infográficas trazem beleza às páginas das publicações (KANNO, 2018, p. 40).
\end{abstract}

De acordo com Richter (2013), os aprendizes que desenvolvem atividades com infográficos obtêm outras capacidades, como: aumento no letramento por meio do incremento visual, construído através da inter-relação do conteúdo textual com a imagem, resultando numa análise crítica da informação comunicada. Outro benefício é a maior habilidade no processamento e na interpretação dos conhecimentos. Ademais, ao se empregar os infográficos, no ensino-aprendizagem do alunado, verifica-se que aqueles interpretam, avaliam, usam e criam mídia visual, como maior criticidade e empregabilidade, que os que usam estratégias metodológicas tradicionais. Dessa forma, observa-se que o aumento no letramento tecnológico, 
de forma criativa, produtiva e efetiva, traz avanços no desenvolvimento cognitivo dos aprendizes.

Para Smiciklas (2012, p. 3), “o infográfico é uma visualização de dados ou ideias que expressa informações complexas para um público de forma que seja rapidamente consumido e de fácil compreensão. " Ainda para o autor, os infográficos são percebidos como boas opções de exposição de informações intricadas em pouco espaço, combinando as vantagens da linguagem verbal com a não-verbal, assim como de outros modelos semióticos2, quando são cunhados no meio digital, a fim de gerar a compreensão e construção do conhecimento.

Dessa maneira, segundo o entendimento de Furst (2010a, p. 35), "um infográfico é um gênero que implica na relação indissolúvel entre texto e imagem, o que diferencia um binômio imagem e texto, que unidos têm uma função de complementaridade. " Esse gênero se apoia na concepção da multimodalidade, já que expõe de diversas formas, que permite uma disparidade de modos de comunicação. Aquele recurso de aprendizagem (Infográfico) que é muito aproveitado no âmbito da comunicação social, vem sendo difundido pela sua facilidade no acesso aos conhecimentos e as informações com clareza e objetividade. Ademais o infográfico prestigia o desenvolvimento cognitivo do leitor, ampliando a sua memória visual. Para efeito de compreensão teórica do gênero infográfico ou, simplesmente, infografia, o estudo o define como sendo a representação de um gráfico de informação, que corresponde a uma imagem visual de um conjugado de dados, podendo esses serem expostos de diferentes formas.

Deste modo, a Geografia, enquanto disciplina curricular, ofertada na Educação Básica, tem atentado, mesmo que de forma ainda pontual, ao seu papel de inovar no processo formativo do ensino-aprendizagem de suas competências, habilidades e conceitos que são primordiais na vida e inserção social e cidadã do educando diversificando na utilização de diversas linguagens como bem salienta Cavalcanti (2013):

Há grandes esforços teóricos e práticos, na estruturação de novos projetos e recomendações curriculares, na prática da pesquisa em Didática da Geografia e na prática de sala de aula para que essa disciplina cumpra seu papel social. Muitos professores têm procurado ser inovadores, nos métodos, procedimentos e linguagens, desenvolvendo aulas em espaços não convencionais, praticando a interdisciplinaridade, utilizando diferentes recursos de forma mais contextualizada com o mundo do aprendiz, avaliando de modo mais qualitativo e formativo. Contudo, essas são ainda práticas pontuais e não predominantes, reforçando o propósito de

\footnotetext{
${ }^{2}$ Semiótica é o estudo dos signos, que consistem em todos os elementos que representam algum significado e sentido para o ser humano, abrangendo as linguagens verbais e não-verbais.
} 
superar alguns desafios que ainda estão presentes no dia a dia da Geografia escolar, para que ela efetive com novos propósitos (CAVALCANTI, 2013, p. 370/371).

Não obstante, vivemos em uma sociedade que se configura cada vez mais na crescente multiplicidade de informações e linguagens, amparadas no processo da revolução-técnicocientífica-informacional (SANTOS, 2006). Diante deste contexto atual a escola tem o importante papel de conferir aos aprendizes um processo de formação que esteja alinhada às novas demandas das dinâmicas globais referentes à comunicação. Visto que, o avanço da tecnologia da informação trouxe novas compreensões da noção de texto, não sendo mais estritamente linear e formal, passando a fazer uso também de imagens, ícones, movimentos, som e diversos outros recursos, passa a definir outras estruturas, a exemplo dos infográficos (JÚNIOR et al., 2014).

Neste contexto, Cavalcanti (2013) aponta que o processo de ensinar e aprender não se restringe apenas às características da linguagem verbal, passando a existir uma variação da linguagem mesclada entre o visual, o verbal e o não-verbal amplamente difundida na sociedade da informação. Portanto, é dever da escola, enquanto instituição promotora da educação integral3, incentivar nos aprendizes o domínio de diversas linguagens, no decorrer do seu processo de formação.

Outro ponto a ser destacado neste encadeamento de ideias, é a facilitação dos infográficos enquanto estratégia de ensino na adaptação aos estilos de aprendizagem (PEREIRA; VIEIRA JUNIOR, 2013) no processo de desenvolvimento das competências.

Logo, amparado nestas considerações, essa proposta de pesquisa sugere discutir, por meio de uma análise científica, as potencialidades do uso de diversas linguagens no processo de aprendizagem dos aprendizes, por meio da construção de infográficos no âmbito do ensino de Geografia. Para isso levanta-se como questão norteadora do estudo a problemática: como a produção de infográficos pode facilitar o processo de aprendizagem dos conteúdos de Geografia dos aprendizes do Ensino Médio?

Assim, o estudo se justifica pela necessidade de pensar um ensino da Geografia que esteja alinhado às novas demandas da sociedade contemporânea em relação à comunicação ao

\footnotetext{
${ }^{3}$ Espaço fechado, com tempo pré-determinado, que compõe a forma escolar no seu aspecto organizacional. Afim de propiciar ao aspecto pedagógico realiza, na produção das "disciplinas" escolares, inter-relações de submissão aos princípios e regras que regem a escola.
} 
fazer uso de vários tipos de linguagens. Por isso os infográficos enquanto ferramentas comunicativas multimodais apresentam-se como recurso de aprendizagem viável para a configuração da sociedade da informação. Visto que, como salienta Paiva (2011), os infográficos, de designação inglesa,4 aliam textos e imagens a fim de transmitir uma informação visualmente atraente para o leitor, ou seja, aos aprendizes, mas com contundência do conteúdo transposto.

Assim, ao se assumir o propósito dos infográficos, pode-se contribuir com a descaracterização que se coloca ao ensino de Geografia, que muitas vezes é rotulado como simplório e enfadonho, já que ao fazer uso de diversas linguagens, por meio dos infográficos, é possível construir um processo de aprendizagem mais significativa, ao possibilitar que os estudantes produzam seus próprios infográficos, o docente permite o contato direto com diversos tipos de linguagens, que podem ser consideradas para compreensão dos assuntos e/ou fenômenos estudados.

Tomando como referência o currículo, ao que se estabelece nos documentos oficiais, a exemplo da BNCC (2018), a proposta de pesquisa ampara-se na definição da educação integral com foco no desenvolvimento de diversas competências e habilidades5. Fato que com a introdução do uso dos infográficos no processo de aprendizagem dos conteúdos trabalhados na Geografia, vai encontro à perspectiva dos documentos normativos, pois ao confrontar o aprendiz, com as múltiplas linguagens, realizam-se a mobilização de diversas competências, valores e atitudes para apreensão dos conteúdos e consequentemente o domínio de diferentes recursos textuais.

Por conseguinte, o desenvolvimento dessa proposta de estudo, se justifica também pelo fato de que se faz necessário pensar uma abordagem do ensino de Geografia, que tenha como pauta a diversidade de linguagem e o uso de recursos digitais. Contribuindo assim, com um ensino-aprendizagem de maior significância ao educando no desenvolvimento de suas competências geográficas.

\footnotetext{
${ }^{4}$ Os resultados da pesquisa mostraram que os sujeitos "possuem um nível considerável de intimidade com gráficos e sua linguagem que mescla números, palavras e formas geométricas” (DUARTE, 2008, p. 112-14).

${ }^{5} \mathrm{Na}$ Base Nacional Comum Curricular, competência é definida como a mobilização de conhecimentos (conceitos e procedimentos), habilidades (práticas, cognitivas e socioemocionais), atitudes e valores para resolver demandas complexas da vida cotidiana, do pleno exercício da cidadania e do mundo do trabalho (BNCC, 2018).
} 
Não obstante, a pesquisa tem por objetivo principal, analisar a produção de infográficos como ferramenta facilitadora do processo de ensino-aprendizagem dos conteúdos de Geografia para os aprendizes do Ensino Médio, da Educação Básica, a fim de vislumbrar a eficiência dessa estratégia metodológica como desenvolvedora das competências geográficas dos aprendizes. Para tal, pontuou seus objetivos específicos: Compreender o que são infográficos e suas aplicabilidades no Ensino Médio, na educação; e, produzir infográficos por meio de plataformas digitais sobre conteúdo de Geografia com aprendizes do Ensino Médio.

Nesta conjuntura o artigo destaca subsídios para uma ponderação sobre o uso do infográfico, como estratégia metodológica de ensino-aprendizagem, no contexto da educação geográfica, em sala de aula. Consequentemente, a linguagem infográfica concebe uma harmonia proveitosa entre textos, imagens e, às vezes, em alguns vídeos, com a finalidade de esclarecer os fenômenos numa abordagem científica.

Para tal, o objetivo do estudo é exibido numa metodologia que será empregada para a efetivação da atividade de leitura do cenário geográfico, o que propiciará o contato com informações que envolvem estruturas de produção e recepção daquele gênero. Sendo o professor responsável por ministrar o conteúdo programado, Infográfico, de forma tradicional, solicitando ao aprendiz que construa o conhecimento, mediado, por meio dessa ferramenta ensinada nas aulas. Aliado a isso, o artigo apresenta atividades que possibilitam o uso do infográfico, no desenvolvimento do aprendiz, ou seja, docente e aprendiz construíram juntos os infográficos, auxiliando os aprendizes, na leitura e interpretação de textos visuais (imagens e gráficos), para que depois de diversificados temas, o alunado possa produzir seus próprios infográficos.

Dessa forma, a pesquisa propõe o uso do gênero infográfico numa indicação de didática ou metodologia de ensino de Geografia, ambicionando motivar a aquisição e a compreensão de conhecimentos por parte dos aprendizes, ao utilizarem o recurso de aprendizagem, como apoio para desenvolver os estudos dos conteúdos da disciplina de geografia. 


\section{METODOLOGIA DA PESQUISA}

Ao perpassar toda a pesquisa, os procedimentos metodológicos traçados para o seu desenvolvimento resultaram em produtos de natureza qualitativa, que teve como objetivo analisar, avaliar e relatar a experiência da intervenção pedagógica, no que diz respeito ao uso e a produção de infográficos, por aprendizes de turmas do $2^{\circ}$ ano, do Ensino Médio, de uma escola em cidade do interior do Ceará, instituição pública vinculada a SEDUC/CE (Secretária de Educação do Estado do Ceará).

A pesquisa enfoca um viés metodológico do tipo qualitativo, visto que não se abordará o levantamento de dados numéricos ou quantitativos. Segundo Silveira e Córdova (2009) a pesquisa qualitativa não se preocupa com representatividade numérica, mas, sim, com o aprofundamento da compreensão de seu objetivo de estudo, e por se tratar também de uma proposta de intervenção pedagógica.

O estudo utilizou o método dedutivo, uma vez que se realiza por meio do desenvolvimento de um raciocínio lógico, que tem por ponto de partida uma ideia geral, uma verdade estabelecida, na qual decorrerão proposições particulares. Esse método parte de teorias e leis para a análise e explicação de fenômenos particulares (geral para o particular) é o que nos ensina Marconi e Lakatos (2010).

As pesquisas exploratórias conforme, ensinamentos de Gil (2009, p. 41) "têm como objetivo proporcionar maior familiaridade com o problema, com vistas a torná-lo mais explícito ou constituir hipóteses". Ainda segundo o autor, a pesquisa bibliográfica é aquela confeccionada por meios de materiais já produzidos, composto especialmente de livros e artigos científicos. A vantagem preponderante de uma pesquisa bibliográfica reside em o pesquisador ter uma gama de fenômenos ao seu dispor, diferentemente do que aquela que poderia pesquisar diretamente.

O documento científico foi elaborado a partir da pesquisa bibliográfica, constituído principalmente de livros, artigos de periódicos, Base Nacional Comum Curricular e da Lei de Diretrizes e Bases da Educação Nacional (LDB 9394/96), além de material disponibilizado nos sites especializados no tema do estudo, respaldados por fontes fidedignas. 
Tomando como base os objetivos traçados, a pesquisa foi qualificada como do tipo descritiva-exploratória, a partir do entendimento de Gil (2008, p. 42) em que, "embora definidas como descritivas com base em seus objetivos, acabam servindo mais para proporcionar uma nova visão do problema, o que as aproxima das pesquisas exploratórias”.

No que tange aos procedimentos metodológicos, foram adotados os seguintes:

- Fundamentação teórica, dos infográficos, relacionadas a temática da pesquisa;

- Intervenção pedagógica para construção de infográficos juntos aos aprendizes por meio de plataformas digitais.

No que se refere a intervenção pedagógica, a mesma, foi realizada mediante sequência didática, considerando primeiramente o currículo da escola, o planejamento docente, os recursos pedagógicos e o calendário letivo escolar. Essa realizada a partir dos passos abaixo:

1. Definição do conteúdo/assunto da Geografia a partir do currículo e planejamento;

2. Oficina de orientação e familiarização aos aprendizes para conhecimento da proposta e ferramentas de elaboração dos infográficos;

3. Pesquisa do conteúdo/assunto em diversas fontes, tais como: livro didático, paradidático e sites da internet;

4. Formação das equipes para produção dos infográficos sobre o conteúdo/assunto definido;

5. Envio dos infográficos produzidos.

As observações e a socialização dos dados foram feitas no período de realização das análises de campo (03/02 a 18/03/2020), que ocorreram no primeiro bimestre (Fevereiro e Março) do ano letivo de 2020, antes da decretação da decretação de medidas restritivas e orientações para distanciamento social (Lockdown) no estado, estabelecido no dia 19 de março de 2020 (19/06/2020). Portanto, as avaliações, oriundas da investigação foram iniciadas e concluídas ainda com aulas presenciais. Todo o processo de pesquisa seguiu as presentes datas:

- 03 a 17 fevereiro exposição de conteúdo nas turmas; 
- 02 a 04 de março realização da oficina;

- 09 a 13 de março pesquisas e construção dos infográficos;

- 16 a 18 de março entrega e socialização.

\section{Construção e Desenvolvimento da Proposta de Ensino dos Infográficos}

O estudo apresenta os caminhos metodológicos e didáticos percorridos nesta experiência de intervenção pedagógica, Figura 1 na disciplina de Geografia no Ensino Médio, por meio do uso e produção de infográficos através de plataformas digitais. Nesse sentido, os procedimentos e caminhos metodológicos narrados neste escrito estão imbricados desde o planejamento, construção e apresentação da proposta. Por se tratar de uma experiência de sala de aula opta-se por desenvolvê-la em forma de sequência didática, considerando primeiramente o currículo da escola, o planejamento docente, os recursos pedagógicos e o calendário letivo escolar.

Figura 1. Esquema de desenvolvimento da proposta.

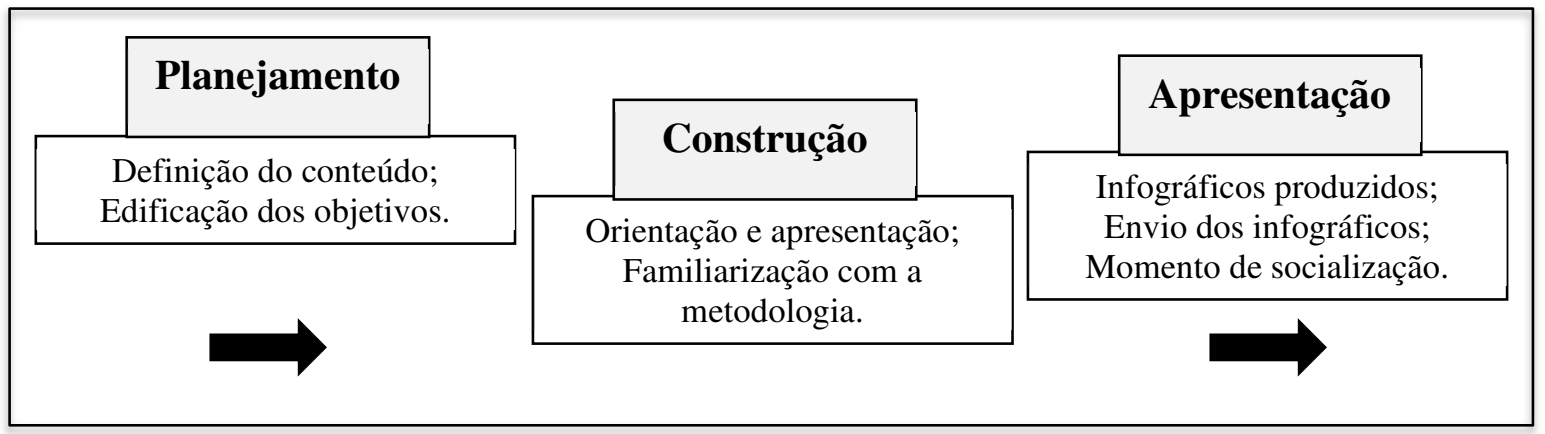

Fonte: Elaborado pelos autores (2020).

Dessa forma a construção da proposta estruturou-se no planejamento, construção e apresentação, colocados em diversos momentos e etapas, os quais estão apresentados no esquema representado e, posteriormente, descritos pela Figura 1.

\section{Planejamento da produção de Infográficos}

O desenvolvimento da proposta foi realizado a partir do planejamento docente, currículo e calendário letivo estabelecido. Assim, de acordo com o planejamento docente e matriz curricular do Ensino Médio que envolvem os conteúdos curriculares da disciplina, o assunto abordado para produção dos infográficos foi a temática do desenvolvimento do sistema 
capitalista, conteúdo definido para o primeiro bimestre letivo das turmas (ano letivo de 2020). Para tal definição foi considerado também o período de aulas realizadas abordando o tema para maior domínio e compreensão por parte dos aprendizes e no processo de aprendizagem e facilitação para produção dos infográficos.

A escolha da plataforma digital para produção dos infográficos se deu a partir de uma busca e observação de suas características para melhor adaptação dos aprendizes no processo de construção, para tanto foi considerado: facilidade de navegação, linguagem, templates disponíveis. Optou-se pela Plataforma Digital Canva, por apresentar linguagem de fácil compreensão, como também por ser uma plataforma multimídia de variação diversa contemplando várias possibilidades, não apenas o recurso do infográfico.

A edificação dos objetivos para desenvolvimento da proposta foi articulada juntamente com o conteúdo, no caso o sistema capitalista, em conjunto com as competências e habilidades sugeridas na BNCC (2018) do Ensino Médio, considerando principalmente a variação de diversas linguagens para compreensão dos conteúdos e saberes geográficos, como possibilitado pelo uso e produção de infográficos.

\section{Elaboração dos modelos de infográficos}

A etapa de construção se iniciou com o desenvolvimento de uma oficina, na qual as turmas em seus horários distintos foram levadas ao laboratório de informática da instituição de ensino. A oficina foi mediada pelo professor regente das turmas, tendo como objetivo explanar sobre as características, uso e aplicabilidade do infográfico. Posteriormente foi apresentada a Plataforma Digital para as turmas. O momento contou com apresentação multimídia de forma a explorar diversos tipos de linguagens, características essenciais para a produção de infográficos. Foi realizado ainda demonstração de interatividade e conexão na Plataforma Canva, realizando uma apresentação sobre sua diversidade e possíveis aplicabilidades, principalmente na construção de materiais multimídia, como no caso dos infográficos.

Posteriormente, foi realizada a apresentação do tema e a proposta de produção de infográficos. Esse momento é considerado importante, pois são levantados diversos questionamentos para motivação dos aprendizes na produção de seus infográficos. É neste momento que se estimula a autonomia do aprendiz no processo de aprendizagem, uma vez que 
o processo de educar pela pesquisa tem como objetivo essencial incentivar o questionamento, a indagação dentro do processo de (re) construção do conhecimento (DEMO, 2002).

Pensando na autonomia dos aprendizes no desenvolvimento do processo de construção do conhecimento, a pesquisa foi realizada tanto de forma individual realizada pelo aprendiz a partir de leitura dirigida no livro didático, quanto coletiva, a partir da divisão de grupos para produção dos infográficos que seria resultado dos estudos realizados.

O desenvolvimento da pesquisa, aconteceu em dois momentos, sendo o primeiro nas dependências da escola sobre orientação docente e o segundo em regime domiciliar visando a autonomia do aprendiz. Foram consideradas diversas fontes para compreensão do tema proposto. Além das discussões em sala de aula ao longo do bimestre, utilizou-se o livro didático, vídeos, paradidáticos e sites a partir de buscas realizadas na internet para maior aprofundamento sobre o desenvolvimento e fases do capitalismo, tema proposto para produção dos infográficos pelos grupos.

A produção dos infográficos sobre o desenvolvimento do capitalismo aconteceu de forma coletiva pelos grupos, na qual os aprendizes tiveram três aulas para realização da pesquisa e elaboração do infográfico da equipe, a contar com o primeiro dia de oficina e orientação para a proposta de ensino.

\section{Apresentação dos infográficos desenvolvidos pelos aprendizes}

A etapa de apresentação culmina na materialização dos infográficos produzidos pelos aprendizes e os resultados de suas pesquisas. Esse momento consiste primeiramente no envio do infográfico em formato digital por meio de correio eletrônico. Em sequência os grupos realizaram a socialização dos seus infográficos produzidos na Plataforma Canva sobre a temática do capitalismo.

É importante destacar que a realização da proposta desde a sua idealização para o posterior desenvolvimento: planejamento, construção e apresentação foi realizada conforme o ritmo pedagógico da escola, como disposto na Figura 2. 
Figura 2. Sequência didática descritiva das etapas do desenvolvimento da proposta.

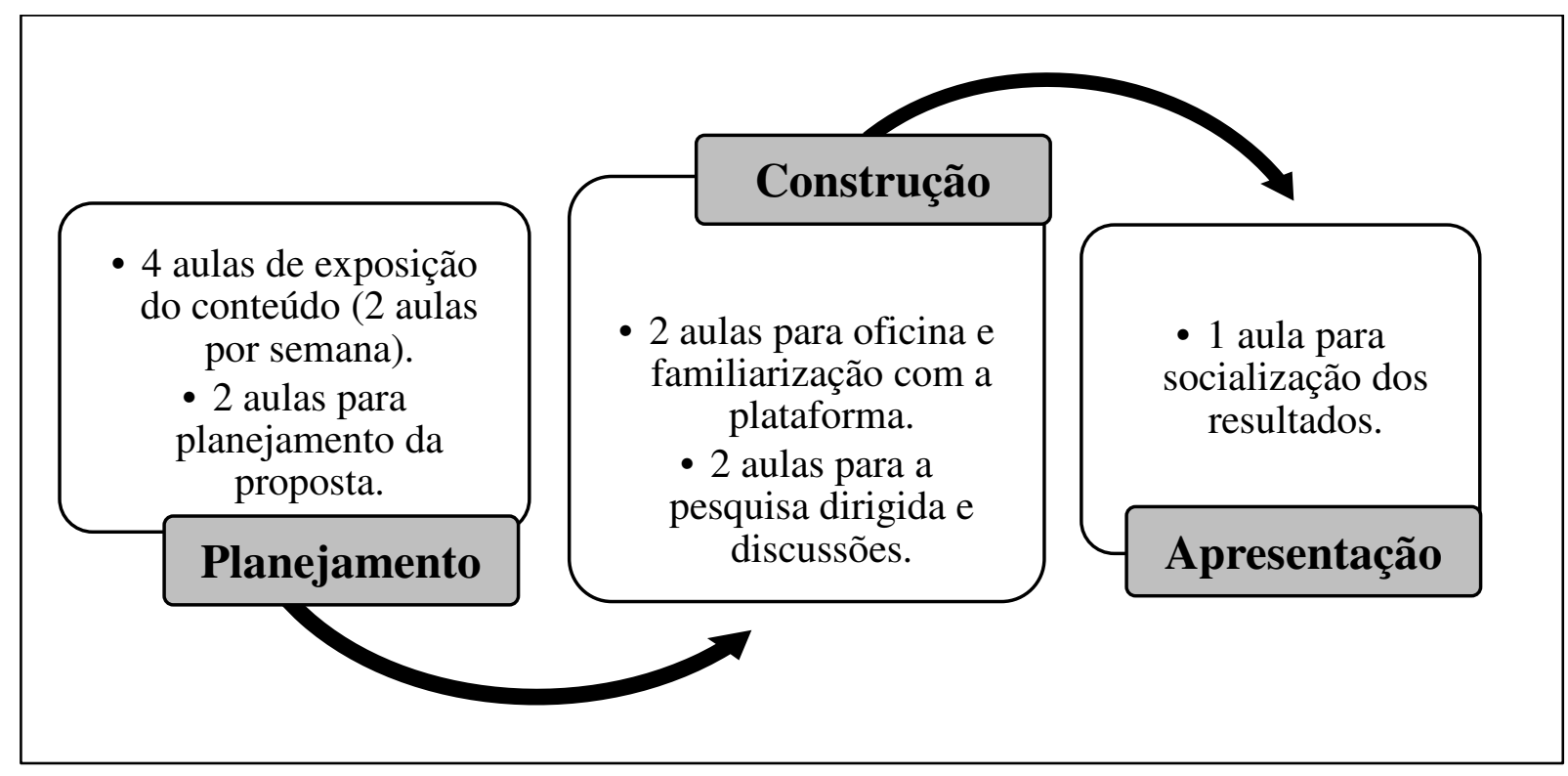

Fonte: Elaborado pelos autores (2020).

O caminho metodológico aqui descrito não é estático, pelo contrário, a indicação de sequência didática é para facilitar a adequação da realidade para melhor aproveitamento do processo de aprendizagem dos diversos conteúdos e saberes da Geografia escolar que podem ser trabalhados a partir das variedades de linguagens, a exemplo dos infográficos, com foco no desenvolvimento de amplas habilidades nos aprendizes para compreensão e análises dos vários fenômenos estudados pela Geografia, como o capitalismo, abordado por hora na proposta de ensino.

\section{INFOGRÁfiCOS E SUAS LINGUAGENS APLICADAS AO ENSINO DE GEOGRAFIA}

$\mathrm{Na}$ atualidade, a discussão sobre espaço geográfico está associada ao contexto do meio técnico científico-informacional, ou seja, da sociedade em rede, sendo assim, qualquer conhecimento mediado aos aprendizes deve, por procedimento didático, ser aplicado tento por base as discussões acerca do espaço geográfico, na visão de Milton Santos (SANTOS, 2008; 2006). Logo, a leitura dos processos socioespaciais permite a arguição sobre a noção de espaço como unidade geográfica fixa, colocando a convivência de ações como uma teia das complexas relações que se constituem, expandindo os horizontes de leitura e reconhecimento da vivência 
das modalidades espaciais que põem em contato a realidade multifacetada da sociedade em sua inter-relação com o espaço (SANTOS, 2008).

Todavia, o cenário atual "batizado" por Castells (1999) de "Era da Informação", iniciou-se em meados da década de 70, coincidindo com três momentos históricos independentes, a saber: revolução tecnológica da informação; crise econômica do capitalismo e do estatismo e consequente reestruturação de ambos; e o apogeu dos movimentos sociais e culturais. Nesse contexto, a revolução tecnológica da informação fez surgir a sociedade em rede, regida por uma economia informacional/global, uma cultura norteada pela virtualização do real, tendo no somatório dos fatos e cenários a materialização da forma atual de sociedade marcada pela inter-relação das informações com as práticas socioespaciais. Tal estrutura social propiciou o surgimento do informacionalismo, base do substrato material de uma nova sociedade.

Não obstante, a principal característica desse informacionalismo é a "sociedade da informação", designação que passou a ser amplamente utilizada pelos meios de comunicação, pois remete ao desenvolvimentismo.

Nesse sentido Rojo (2015), Teixeira (2010; 2007), Gonçalves (2007), avaliam como as características da informação podem ser organizadas:
a) Atual - A informação deve ser contemporânea para que se possa tomar as decisões de forma acertada;
b) Relevante - a informação deve ser importante para que a pessoa precise dela;
c) Disponível - a informação deve estar acessível, no momento certo, possibilitando o rápido acesso;
d) Legível - a informação deve ser de boa qualidade de visualização e compreensão;
e) Oportuna - a informação deve estar certa no momento certo;
f) Correta - a informação deve está livre de erros para não afetar sua fiabilidade; e
g) Fiável - a informação deve ser imparcial, objetiva, precisa e verificável.

Na pesquisa, no Ensino de Ciências, muito se debate acerca das melhorias nas práticas de ensino existentes, repensando a formação de professores, reestruturando os currículos, com a ambição de construir uma educação em que o aprendiz seja ativo e participativo, tendo autonomia e criticidade no processo de aprender.

A assimilação da pesquisa, em sala de aula, vai além dos enfoques tradicionais, ao desvincular as práticas pedagógicas das aulas de bancada (aulas copiadas), desenvolvendo 
assim, a formação crítica, participativa e arraigada com a realidade do educando, quando perpetuada com a abordagem temática, pode obter resultados bastante significativos.

Nesse processo de reconstrução de conhecimentos, uma ferramenta que pode ser utilizada em sala de aula, por meio da estratégia de aprendizagem significativa, é o infográfico. Visto que ele é um meio de transformação de dados adquiridos numa pesquisa, que muitas vezes parecem fazer pouco sentido, em informações organizadas, possibilitando ao leitor/aprendiz melhor compreensão daquelas (COSTA; TAROUCO, 2010). É devido a esta capacidade em sistematizar os conhecimentos pesquisados, ao se fazer uso da imagem, som, gráficos entre outros elementos, que este instrumento pedagógico promove um trabalho coletivo e interdisciplinar entre as várias áreas da ciência, uma vez que busca e discute os múltiplos temas.

O uso de uma estratégia metodológica pautada em infográficos tem como desígnio a transversalidade, preconizando a constituição do cidadão e da sua educação num significado mais alargado, não apenas restrito aos conteúdos específicos (ROJO, 2013). É nesse contexto que a infografia ou os infográficos, são utilizados como formas de reprodução/visualização do conhecimento, pois esses são uma ferramenta muito utilizada, nas mais distintas áreas do saber científico, porque permitem analisar um fato de forma pormenorizada, ao combinar múltiplos recursos multimídia (mapas, gráficos, textos, áudios, vídeos, desenhos, fotografias, documentos digitalizados, entre outros) para exibir uma informação (CERIGATTO; MEDEIROS; SEGURADO, 2010).

Para se fazer compreender ROJO (2012), destaca que os infográficos possuem como características de produções que são: interativas; colaborativas; transgridem as relações de poder, bem como as relações de propriedade, são híbridas, multilinguagens, modos, mídias e culturas.

Nesse aspecto Furst (2010b, p. 2) explica que "o infográfico é um texto que apresenta a informação, aliando de maneira a palavra à imagem. " Já para Módolo (2007, p. 5) o “termo infográfico vem do inglês informational graphics e alia texto e imagem a fim de transmitir uma mensagem visualmente atraente para o leitor, mas com contundência de informação. "

Amaral (2009) enfatiza que os infográficos evoluíram ao longo dos tempos. O autor considera que esse tem quatro gerações, sendo elas:

i) a primeira geração - a informação organizava-se de forma linear; 
ii) a segunda geração - começaram a ser utilizados as hiperligações e animação;

iii) a terceira geração - que coincide com o aparecimento dos primeiros recursos multimídia; e,

iv) a quarta geração (atual), identifica-se pelo uso de base de dados e a interatividade proporcionada pela Web 2.0.

Como se pôde constatar, ainda que exista alguma polissemia em torno do conceito, os autores aderem a uma das características básicas do conceito do infográfico, ou seja, aquela em que a representação da informação, com auxílio de recursos, que podem ser imagens, ícones, meios informáticos e multimídia, é materializada. Paralelo a isso, tem-se os progressos tecnológicos, os quais estruturam as inter-relações humanas na atualidade, as mesmas que transformam o trabalho pedagógico, ao proporcionar e ampliar o aparecimento de novas capacidades de ensino.

Santos (2006) ressalta a relevância de efetivar uma discussão acerca da proposta de divisão regional fundamentada na distinção do meio técnico-científico-informacional, assim como nas heranças do passado brasileiro, que possibilitou que cada região, que compõe rugosidades do espaço geográfico, dilatar os fluxos, na qual a acomodação das infraestruturas e redes informacionais realiza-se de modo descontínuo.

Diante do exposto, pensa-se o infográfico como instrumento na mediação do conhecimento, no meio educacional, ao perceber que favorece o entrosamento dos conteúdos curriculares, da disciplina de Geografia, tendo em vista a leitura e apreensão de temas curriculares dessa disciplina.

\section{RESULTADOS E DISCUSSÕES}

A produção dos infográficos na disciplina de Geografia, sobre o capitalismo levou uma série de fatores em consideração. Primeiramente, como apontado, é papel da escola interligar o educando aos contextos do mundo globalizado frente a era da informação (CASTELLS, 1999). Em segundo lugar, destaca-se que o desenvolvimento de competências e habilidades com foco nas mídias digitais e tecnologias (BNCC, 2018) devem ser entendidas como papel da escola na conexão com o mundo global. Neste contexto desenvolver metodologias de ensino/aprendizagem que coloquem o aprendiz como sujeito ativo de seu processo, fazendo 
ligação com as diversas linguagens oriundas do período da comunicação e informação, se fazem necessárias para o desenvolvimento de habilidades.

\section{Produção de infográficos a partir de plataformas digitais}

$\mathrm{Na}$ fase de planejamento da proposta, considerou-se a necessidade de desenvolver nos aprendizes o domínio de diferentes linguagens (verbal, não-verbal, simbólica), para além da tradicional linguagem escrita. Por isso viu-se no recurso de infográfico a possibilidade de realizar a junção de outras linguagens difundidas na atualidade, a exemplo das imagens, ícones, gráficos, dentre outros recursos não verbais, que quando usado em conjunto permitem a compreensão de conteúdo/assuntos de forma mais fácil e interativa.

Outro fator, também alinhado no desenvolvimento de habilidades e competências (BNCC, 2018) é que a proposta de produzir infográficos leva o aprendiz a experimentar diversos estilos de aprendizagem ao longo da sua construção, tendo em vista que ao desenvolver sua pesquisa para fundamentar seu produto, depara-se com diversas linguagens para entendimento do assunto proposto, no caso em questão o capitalismo, não apenas em questão das linguagens mas também no compartilhamento dos conhecimentos construídos, possibilitado pelo agrupamento de pares/equipes para construção.

Nesse contexto, como destaca Bottentuit, Lisboa e Coutinho (2011), a utilização de infográficos poderá ser um grande contributo para o ensino e aprendizagem de diversos tipos de conteúdo, em especial aqueles que visam descrever uma sequência de ações, como no caso do conteúdo transposto na proposta.

Concomitantemente, é preciso acrescentar que os infográficos produzidos pelos aprendizes não devem ser considerados apenas um conjunto de tabelas, cores, desenhos, fotos com o intuito de deixar o recurso mais atrativo visualmente (MÓDOLO, 2007). É preciso considerar as inter-relações entre as diversas linguagens utilizadas pelos aprendizes para explicação do fenômeno geográfico estudado, pois cada texto, ícone ou figuras colocadas para compreensão do assunto, possuem significado para os aprendizes e são ainda resultado do desenvolvimento da pesquisa enquanto princípio educativo da aprendizagem (DEMO, 2009) que possibilita a autonomia a partir dos questionamentos e facilita a construção do conhecimento de forma mais significativa para o aprendizado. 
Como já narrado, no presente escrito, a produção de infográficos ocorreu com aprendizes do Ensino Médio, por meio do uso da Plataforma Digital Canva, contudo antes de as discussões em relação ao processo de construção realizado pelos aprendizes se iniciem, é preciso que se destaque que o infográfico enquanto recurso comunicativo não era objeto de desconhecimento no contexto educacional dos aprendizes, pois apresentava-se como componente ilustrativo de diversas seções e capítulos do livro didático de Geografia utilizado em sala de aula. Entretanto era um recurso textual pouco explorado, pelo professor, para desenvolvimento da aprendizagem de diversos conteúdos trabalhados pela Geografia escolar.

Paralelamente, os motivos da não utilização do infográfico, é porque não se considerava o infográfico uma estratégia didática viável para o ensino, uma vez que era proveniente dos textos jornalísticos e pouco conhecido no âmbito educacional, principalmente, na disciplina de geografia. Dessa forma, o intento da pesquisa foi investigar as linguagens utilizadas pelos infográficos na condução do conteúdo abordado e as formas de expressa-las no ensino-aprendizagem.

Ao todo foram construídos 30 (trinta) infográficos pelos grupos formados nas três turmas nas quais foi desenvolvida a proposta de produção de infográficos. Os aprendizes, ao fazerem uso do laboratório de informática da instituição, tanto para realização da pesquisa sobre o desenvolvimento do capitalismo, como para a construção de seus infográficos, utilizaram templates disponibilizados na plataforma ou construíram seus próprios modelos.

A Plataforma Digital Canva, mostrou-se bastante interativa, apresentando facilidade de manuseio de suas ferramentas. A interface é de fácil compreensão, possibilitando com que os aprendizes de forma coletiva pudessem materializar suas ideias de forma inovadora e criativa na produção dos infográficos de suas equipes, seguindo as etapas e momentos propostos pelo professor no ato de realização da oficina e apresentação da proposta metodológica de ensino.

Ao longo de todo o processo de desenvolvimento da sequência didática que resultou na construção de infográficos para compreensão do capitalismo e seu processo de expansão, foi possível verificar a consistência da pesquisa motivada para embasamento teórico e aprofundamento do tema, tendo em vista que todos os infográficos, a exemplos dos demostrados na Figura 3 abordam uma evolução histórica-econômica do capitalismo. 
Figura 3. Exemplos de infográficos produzidos pelos aprendizes sobre o capitalismo.

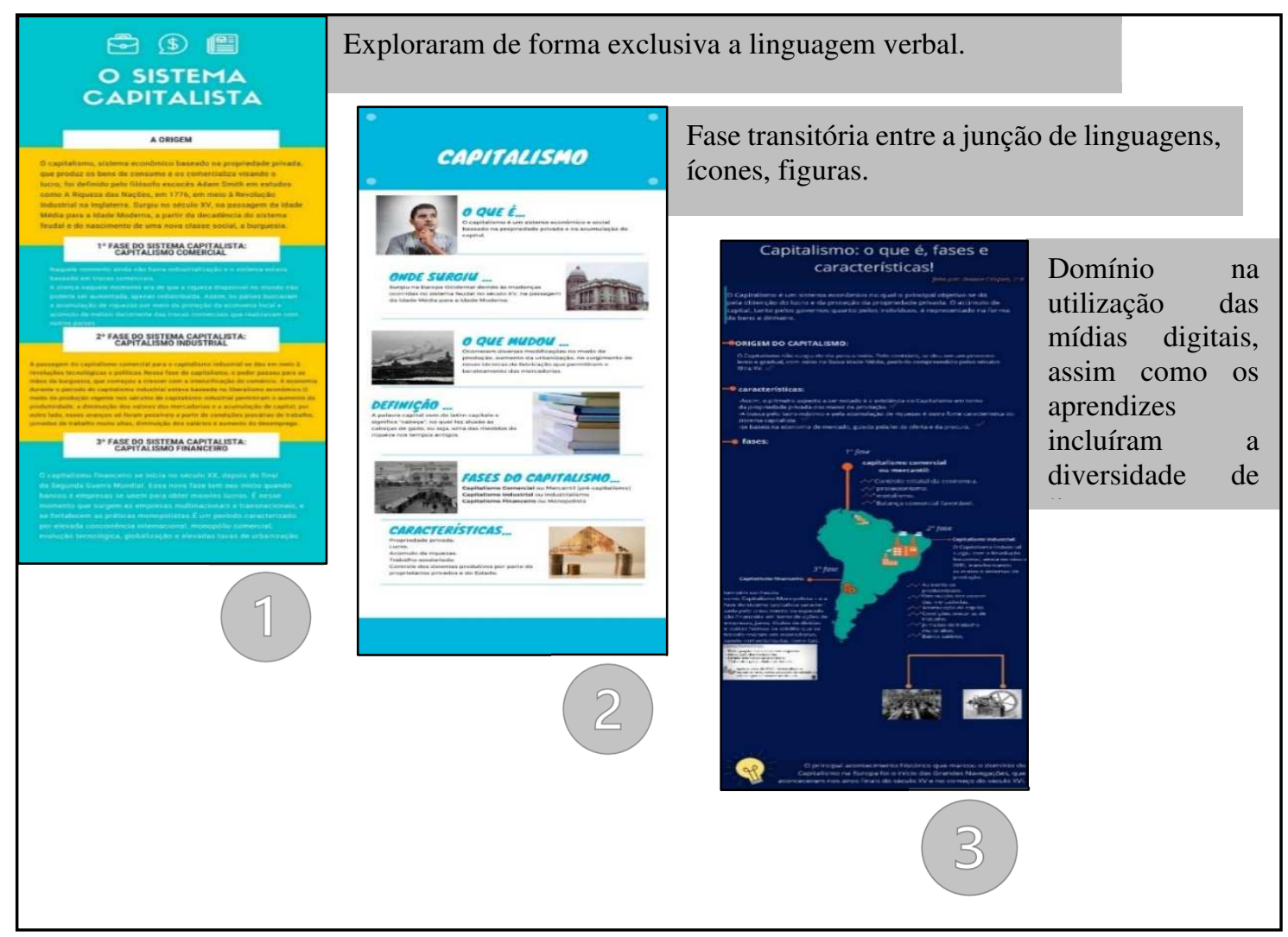

Fonte: Elaborado pelos autores (2021).

Já em relação à variação de linguagens e uso de recursos simbólicos para explicação do tema e ilustração dos infográficos, nota-se que houve uma variação em todos os 30 (trinta) infográficos produzidos pelos aprendizes. Como demostrado na Figura 3, alguns grupos exploraram de forma exclusiva a linguagem verbal, fator que pode levar a crer que esses aprendizes têm maior facilidade com textos sintéticos para compreensão e explicação de assuntos. Em uma fase transitória entre a junção de linguagens, ícones, figuras está o segundo infográfico apresentado, representando aqueles aprendizes que tem facilidade com a transposição de assuntos tanto por meio do uso da tradicional linguagem verbal escrita quanto a linguagem não-verbal.

Outro ponto observado a partir do uso e produção dos infográficos é a sua capacidade de influenciar nos estilos de aprendizagem dos aprendizes. Nesse contexto entende-se que cabe ao professor planejar momentos em que possam adaptar suas metodologias aos estilos preferencias dos aprendizes de modo a facilitar o entendimento dos conteúdos, como no caso o 
desenvolvimento do capitalismo, possibilitando momentos propícios ao exercício de diversas habilidades.

O uso dos infográficos para o processo de aprendizagem na disciplina de Geografia possibilitou a vinculação de diversos polos de entradas em relação aos estilos de aprendizagem, tais como na percepção, entrada, processamento e entendimento devido sua característica de mídia multimodal. Contudo chama bastante atenção o polo de entendimento, visto que a maioria dos infográficos produzidos pelos aprendizes realizou a apresentação do capitalismo de forma sequenciada, fator que revela um predomínio e preferências das turmas experienciadas pela compreensão dos fenômenos geográficos estudados de forma sequencial.

Tal observação é válida ao professor, pois como destaca Pereira e Vieira Junior (2013, p. 186) “(...) as características de cada estilo de aprendizagem permitem aos professores uma variação metodológica no ensino que pode ser extremamente útil na prática de sala de aula." Nesse sentido, o uso e produção de infográficos pelos aprendizes tornou-se campo frutífero para a variação metodológica e reflexão da prática.

Percebe-se, ainda, ao se observar o último infográfico de produção dos aprendizes, posto na Figura 3 um domínio maior da utilização das mídias digitais e nelas incluídas a diversidade de linguagens aqui já relatadas. Neste último em maior sintonia e esquematização para explicação da evolução do capitalismo desde seu início até a contemporaneidade.

É preciso salientar que ao se tratar de uma proposta metodológica de ensino voltado para compreensão de assuntos por meio do uso de Plataforma Digital com diversas mídias e linguagens, os aprendizes que mesclam mais elementos gráficos integrados ao seu texto conseguiram construir e ressignificar conhecimentos a um nível mais elevado que os aprendizes com que limitam exclusivamente ao recurso gráfico da escrita na construção de seu infográfico.

Apesar destas características, observou-se que todos os infográficos produzidos apresentaram substancial conhecimento acerca do capitalismo, fator que denota efetiva aprendizagem por meio do processo de interação entre conhecimentos já pré-existentes no grupo de aprendizes em relação ao tema abordado e os novos conhecimentos gerados, a partir da metodologia utilizada, bem como a cooperação por ter sido realizada em equipes, ou seja o princípio de uma aprendizagem significativa. 
Para que essa aprendizagem no momento de produção dos infográficos aconteça de modo significativo, assim, a integração entre o gênero multimodal infográfico e o ensino tornase relevante, pois possibilita e demanda novas estratégias do uso combinado de informações, a fim de favorecer o processo de ensino-aprendizagem, como no caso experienciado a partir da disciplina de Geografia com aprendizes do Ensino Médio.

\section{CONCLUSÃO}

O uso dos infográficos como ferramenta didática-pedagógica como facilitadora da aprendizagem de diversos assuntos escolares vem corroborar com a mudança do cenário educativo. Ao incorporar essa técnica de linguagem mista e sua produção por meio de aplicativas e ou programas de mídias facilita-se a compreensão de diversos assuntos do currículo escolar, pois possibilita que o aprendiz utilize de sua criatividade fazendo uso de diversas linguagens para apresentação dos assuntos trabalhados em sala de aula.

Observa-se que a utilização de novas linguagens comunicativas e inserção de tecnologias da comunicação e informação no contexto escolar podem mudar esse cenário e auxiliar na facilitação de conteúdos abstratos e teóricos aos aprendizes. Diante disto o uso de infográficos mostrou-se como uma ferramenta didático-pedagógica, pois possui uma linguagem visual diversificada para explicar diversos assuntos.

Não obstante, com base nestas constatações, considera-se o uso e produção de infográficos por meio de plataformas digitais como mais uma ferramenta tecnológica que o professor em seu saber/fazer docente na disciplina de Geografia pode lançar mão. Diante disso, destaca-se diversas potencialidades do infográfico enquanto ferramenta didática, primeiro na possibilidade de união de diversos estilos de aprendizagem para os aprendizes, ao fazer uso tanto das várias linguagens verbais, não-verbais e gráficas, quanto na utilização de tecnologias e mídias digitais.

Destaca-se ainda a contribuição para um processo de ensino que leva em consideração a autonomia do aprendiz de modo a permitir uma construção interativa do conhecimento e ainda de cunho significativo. No tocante ao desenvolvimento de habilidades e competências, observou-se que o processo de construção de infográficos instiga o aprendiz na percepção e 
compreensão de diversos assuntos sobre a ótica da variação de linguagens, fator que contribui para seu desenvolvimento intelectual e pessoal no contexto da era da comunicação e informação.

Tais potencialidades aqui destacadas estão internamente relacionadas na ação docente, uma vez que os infográficos, tal como outras ferramentas tecnológicas e digitais existentes podem oferecer diversas potencialidades educativas, mas sua utilização em contexto educativo de forma construtiva vai depender da criatividade do professor a fim de que seja possível alcançar os objetivos propostos.

Portanto, ao desenvolver a presente proposta de ensino, acredita-se que o principal impacto está no processo de construção do conhecimento, pois ao proporcionar aos aprendizes o desenvolvimento um estudo em modelo pautado no educar pela pesquisa caracteriza um caráter dinâmico e emancipatório em seu processo de aprendizagem.

Finalmente, foi verificada a existência de uma valorização das novas tecnologias da informação e comunicação dentro do contexto escolar, pois dado o exposto, a tecnologia na contemporaneidade já é uma realidade presente no cotidiano dos aprendizes, principalmente, frente as novas tendências e eclosão de comunicação e comportamentos digitais. Neste sentido o infográfico apresenta diversas potencialidades para uso como ferramenta de ensino, não apenas para explicar o capitalismo e suas fases de desenvolvimento, mas de diversos assuntos/conteúdos que se fazem presente na Geografia escolar.

\section{REFERÊNCIAS}

AMARAL, R. C. G. Limites dos infográficos jornalísticos na Web: sistematização preliminar de características distintivas e produtos semelhantes. In: CONGRESSO BRASILEIRO DE CIÊNCIAS DA COMUNICAÇÃ̃O, 32, Curitiba. 2009.

BRASIL - Ministério Da Educação. Secretaria de Educação Básica. Programa Ensino Médio Inovador: Documento orientador. Ministério da Educação. Secretaria de Educação Básica: Brasília, 2013.

BRASIL - Base Nacional Comum Curricular: Ensino Médio. Brasília: MEC/Secretaria de Educação Básica, 2018.

BOTTENTUIT, J. B. Jr.; LISBOA, E. S.; COUTINHO, C. P. O infográfico e as suas potencialidades educacionais. Quaestio, Sorocaba, p. 163-183, nov. 2011. 
CASTELLS, M. A sociedade em rede. São Paulo: atualizações para $6^{\circ}$ edição, 1999.

CAVALCANTI, L. de S. Os conteúdos geográficos no cotidiano da escola a meta de formação de conceitos. In: Albuquerque, M. A. M. de; Ferreira, J. A. D. S; (Org.). Formação, pesquisa e Práticas docentes: Reformas curriculares em questão. João Pessoa. 1 ed. Editora mídia. 2013.

CERIGATTO, M. P.; MEDEIROS, M. F.; SEGURADO, V. Infografia e Educação a Distância. In: SÁNCHEZ, J. (ed.). CONGRESO IBEROAMERICANO DE

INFORMÁTICA EDUCATIVA, Santiago de Chile. v. 1. p. 146-149. 2010. Disponível em: <http://www.ie2010.cl/posters/IE2010-138.pdf.> Acesso em: 15 mai. 2020.

COSTA, V. M.; TAROUCO, L. M. R. Infográficos, características, autoria e uso educacional. In: Revista Novas Tecnologias na Educação. CINTED-UFRGS, v.8 n³3, dezembro de 2010.

DEMO, P. Educar pela pesquisa. 9. ed. Campinas, SP: Autores Associados, 2002.

DUARTE, V. M. Textos multimodais e letramento. Habilidades na leitura de gráficos da Folha de São Paulo por um grupo de aprendizes do ensino médio. 219p. Dissertação (Mestrado em Estudos Linguísticos). Universidade Federal de Minas Gerais, 2008. Disponível em: http://www.bibliotecadigital.ufmg.br/dspace/handle/1843/ARCO-7FVRTQ. Acesso em: 13 jun. 2021.

FURST, M. S. B. C. Infográficos: habilidade na leitura do gênero por aprendizes de ensino médio. Faculdade de Letras da Universidade Federal de Minas Gerais, (Dissertação, Mestrado em Estudos Linguísticos). 2010a.

FURST, M. S. B. C. Infográfico: Características, autoria e uso educacional. Revista Novas Tecnologias na Educação, Porto Alegre, v. 8, n. 3, p. 1-14, Dezembro 2010 b.

GIL, A. C. Como elaborar projetos de pesquisa. 6. ed. São Paulo: Atlas, 2008.

GIL, A. C. Métodos e técnicas de pesquisa social. 6 ed. São Paulo: Atlas, 2009.

JÚNIOR, O. F. da S., et al., O lugar dos infográficos no processo de ensinar e aprender geografia no ensino médio. In: OLIVEIRA, Francisca de Fátima Araújo; GONÇALO, Edinaldo Tibúrcio; SOEIRO, Maria Isaura Plácido (Org.). Prodocência na UERN: novas perspectivas para a formação de professores e a melhoria da educação básica. Mossoró: Edições UERN, 2014. p. 243.

KANNO, M. Infografia. Guia básico para didáticos. 1a ed. Edição do Kindle. São Paulo: Boreal Edições, 2018. 
LIMA, G. A. de; CATELÃO, E. de M. Infográfico: produção e possibilidades no uso educacional do ensino de Geografia. Ensino e Tecnologia em Revista, Londrina, v. 3, n. 1, p. 01-20, jun. 2019.

MARCONI, M. de A.; LAKATOS, E. M. Metodologia científica. 6.ed. São Paulo: Atlas, 2010.

MÓDOLO, C. M. Infográficos: características, conceitos e princípios básicos. In: XII CONGRESSO BRASILEIRO DE CIÊNCIAS DA COMUNICAÇÃO DA REGIÃO SUDESTE, 12. Juiz de Fora. 2007. Disponível em:

<http://www.intercom.org.br/papers/regionais/sudeste2007/resumos/R0586 1.pdf. $>$ Acedido em: 14 mai. 2020.

PAIVA, F. A. O gênero textual infográfico: leitura de um gênero textual multimodal por aprendizes da $1^{a}$ série do ensino médio. Revista L@el em (Dis-)curso, v. 3, n. 1, p. 87-101, jun. 2011.

PEREIRA, E. J.; VIEIRA JUNIOR, N. Os Estilos de Aprendizagem no Ensino Médio a partir do Novo ILS e a Sua Influência na Disciplina de Matemática. Alexandria: Revista de Educação em Ciência e Tecnologia, Florianópolis, v. 6, n. 3, p. 173-190, nov. 2013.

RICHTER, S. Teaching with infographics. Slideshare.net, 15 oct. 2013.

Disponível em: <http://www.slideshare.net/srichter/teaching-with-infographics-27211531>. Acesso em: 10 mai. 2020.

ROJO, R. (Org.) Pedagogia dos multiletramentos: diversidade cultural e de linguagens na escola. In: ROJO, R.; MOURA, E. (Org.). Multiletramentos na Escola. São Paulo: Parábola Editorial, p. 11-31. 2012.

ROJO, R. (Org.) Escola Conectada, os multiletramentos e as TICs. São Paulo: Parábola, 2013.

ROJO, R. (Org.). Hipermodernidade, multiletramentos e gêneros discursivos. São Paulo: Parábola Editorial, 2015.

SANTOS, M. A natureza do espaço: técnica e tempo, razão e emoção. 4.ed. São Paulo: EdUSP, 2006.

SANTOS, M. Espaço e Método. São Paulo: Editora da Universidade de São Paulo, 2008.

SANTOS NETO, J.; ALMEIDA JÚNIOR, O.; VALENTIM, M. SOCIEDADE DA INFORMAÇÃO, DO CONHECIMENTO OU DA COMUNICAÇÃO? A questão da apropriação da informação. INFORMATION SOCIETY, THE KNOWLEDGE OR COMMUNICATION? issues of information's appropriation. Anais do V SECIN, 2013, p. $179-197$. 
SILVEIRA, D. T.; CÓRDOVA, F. P. Unidade 2 - A pesquisa científica. Porto Alegre: Editora da UFRGS, 2009.

SMICIKLAS, M. The Power of Infographics. Using pictures to communicate and connect with your audience. Indiana: Que, 2012.

TEIXEIRA, T. A presença da infografia no jornalismo brasileiro: proposta de tipologia e classificação como gênero jornalístico a partir de um estudo de caso. Revista Fronteiras, v. 9, 2007.

TEIXEIRA, T. Infografia e jornalismo: conceitos, análises e perspectivas. Salvador: EDUFBA, 2010. 